of chance, moreover, it generally happens that two meetings occur with just an interval of one day between them, which makes it still more difficult to attend either.

Would it not be possible to fix one day, namely, Friday afternoon and evening, as a general day of meeting for the societies? This would, I feel sure, allow many provincial members to come down to London for the occasion, partly because they could merge the Friday with their " weekend," and partly because they might have the chance of attending several meetings the same afternoon and even ing. I doubt whether such an arrangement would inconvenience many of the London members; but, even if it does, the London members might perhaps be willing to give way, because to them, in any case, attendance is much more easy than it is to men who live perhaps hundreds of miles away. I have discussed the matter with several friends in.Liverpool, all of whon seem to be favourably impressed with the idea.

Johnston Tropical Laboratory, University of Liverpool, February 5.

\section{The Meaning of "Ionisation."}

IN his interesting notice concerning the work of Arrhenius, published in Nature of February 3, Prof. Walker, in a somewhat ambiguous manner, refers to "the notion and practical definition of degree of ionisation "' as the great positive contribution of the distinguished physicist. "Whatever be our views of the origin and nature of ions, we must" ... - - he says-" have recourse to the notion of degree of ionisation." It is a little difficult to see how we are to have recourse to a notion if we are not clear what view that notion is based upon and includes. To appreciate Prof. Walker's position, it is essential that we should know precisely what meaning he attaches to the words I have quoted-what conception underlies them. I would beg Prof. Walker to tell. us, in clear, unmistakable terms, what exactly he would have us understand by the word ionisation.

When the Royal Society has completed its Catalogue of Scientific Papers of the last century, it will doubtless be compelled to prepare a dictionary in explanation of the terminological inexactitudes to be found in its Proceedings and other journals; of these, ionisation will be one of the most difficult to interpret. Prof. Walker will render real service if he will tell us in what sense or senses he uses the word throughout his notice; does he or does he not use it as connoting explicitly the separation of a substance in solution into several portions, each capable of acting as a distinct kinetic unit? This, I believe, was the doctrine enunciated by Arrhenius in $188 \%$, and which, if I mistake not, he still professes. Does Prof. Walker advocate such doctrine?

Henry E. Armstrong.

Prof. Armstrong and I look at ionisation from different points of view. He is chiefly interested in an interpretation of the process and phenomena of ionisation in terms of the kinetic molecular theory. I am chiefly concerned to have a theory, whatever be its exact mechanical interpretation, which is capable of berng mathematically formulated and of acting as a guide in quantitative investigation. My position, in short, is that of the astronomer who is content to have Newton's law for practical purposes, and only takes a speculative interest in theories of the nature of gravitation.

Possibly the best analogue in physics to Arrhenius's theory of electrolytic dissociation is van der Waals's theory of the continuity of the gaseous and liquid states. Van der Waals's theory can be put in the form of a comparatively simple equation which is very successful in representing the facts in broad general outline, though in many cases it proves to be imperfect in detail. Although the kinetic molecular assumptions on which van der Waals based his theory may be questioned, his equation will remain an important aid to investigation in its special tomain until it is superseded by another of comparable simplicity and of greater comprehensiveness.

$$
\text { JAMES WALKER. }
$$

\section{The Invention of the Slide Rule.}

IN NATURE of January I3 (p. 307) Dr. Alexander Russell, in writing of the invention of the slide rule, says :- "Supporting the latter view is the fact that he (Oughtred) published ( 1633$)$ his 'Mathematicall Recreations' under the pseudonym of Henry Van Etten." This evidently implies that Oughtred was the author of the said "Mathematicall Recreations," whereas the very title of the work shows that it was a translation, and not an original contribution. It reads :- " Mathematicall Recreations; or a collection of sundrie problemes and experiments in arithmeticke, cosmographie, astronomie, architecture, chimistrie, \&c., extracted out of the ancient and moderne philosophers, now delivered into English tongue with the examinations, corrections and augmentations by W. Oughtred."

The italics are ours. The translation was made from the French of Henry Van Etten's " Recreation Mathematique, composee de plisieurs problemes, plaisants et facetieux, en fait d'Arithmétique, Geometrie, Mecanique, Optiq.; et autres parties de ces belles Sciences." The accents are missing in the title-page. The work was published in Paris in 1624. The name of Henry Van Etten is indeed a "sseudonym," but it is that of Jean Leurechon (I591r69o), a French Jesuit of uncommon mathematical versatility and not that of William Oughtred (I574-I660), an English divine of no less uncommon mathematical ability. Brother Potamian.

Manhattan College, New York City, January 27.

\section{Transit of Halley's Comet.}

May I point out that at the time of the transit of Halley's comet the sun will be above the horizon at the North Cape? The Cape is distant $18^{\circ} 49^{\prime} 20^{\prime \prime}$ from the pole, and the declination of the sun at midnight of May is will be $19^{\circ} 3 x^{\prime} \cdot 42^{n}$; adding $27^{\prime} 22^{\prime \prime}$ for refraction, the sun's altitude at midnight would be $1^{\circ} 9^{\prime} 44^{\prime \prime}$, and the attitude would increase before the first contact, which will take place at $x 6 \mathrm{~h} .6 \mathrm{~m}$. local time. The Cape rises to a height of 968 feet, and there should be a very fair sporting chance of seeing something of whatever there may be to see during the sixty minutes' duration of the transit.

Banwell Vicarage, Somerset, February Ir.

$$
\text { C. S. TAYLOR. }
$$

\section{Dangerows Lecture Experiments.}

Although it is no part of my duty to teach chemistry, I have on several occasions had to perform an experiment which Mr. Marle quotes (p. 428) as being dangerous, viz. the collection of hydrogen from the action of sodium on water. I can fully endorse his warning. Twice a violent explosion took place; but I found that if the piece of sodium is carefully cleaned so that all its surfaces are bright, and cold water used, the experiment can be carried out in safety. I do not know if these important details have found their way into the practical manuals in use in chemical laboratories. If not, I trust that this experiment is not one that beginners are directed to make.

Eton College, Windsor, February $1 \mathrm{r}$.

M. D. Hill.

\section{Aged Tadpoles.}

LAST year I reared about five thousand tadpoles, and, dividing them into twenty portions, brought most of them to the frog stage. As they matured, and the numbers became smaller, the survivors were gradually brought together again into a few vessels, finally into one. Of those which were in the tadpole stage in November, none changed to frogs. They died one by one until only two are left. These are quite healthy-active feeders with long tails and hind legs, but no appearance of fore legs. Perhaps some of your readers will be able to say whether it is usual to have tadpoles a year old, and whether one may expect any change to take place now-whether, perhaps, like Axolotl, they may not exhibit the power of reproducing their own kind if they remain alive.

Carrick Academy, Maybole, N.B.

JOHN DON. 